\title{
Impact of labour market liberalisation on minimum wage effects: The case of the construction sector in a small open economy
}

\author{
Luzius Stricker, Moreno Baruffini
}

\begin{abstract}
A B S T R A C T
Objective: The objective of this article is to estimate the impact of the application of the bilateral agreement of Free Movement of Persons between Switzerland and the EU-15 countries on the labour market outcomes in the Swiss main construction sector. The analysis happens in the context of increasing minimum wage levels in the industry.

Research Design \& Methods: The included treatment variable, the minimum wage bite, is compared to the growth of sectoral employment. We conduct two specifications of a Difference-in-Difference model, controlling for different characteristics and spatial spillover effects.
\end{abstract}

Findings: The results show that the introduction of the Free Movement of Persons reduced the growth rate of employment in the construction sector compared to the growing minimum wage bites, considering the cantons as a box. The results for the specification, including spillover effects, suggest that the employment variation in construction is guided in large part by the local and interregional economic trends.

Implications \& Recommendations: While in open market construction firms do not dispose of instruments to cover higher wages, a country sealing off its markets from an interconnected economic space could pay minimum wages above the marginal productivity of its workers.

Contribution \& Value Added: Making use of an exogenous institutional change, we contribute to the evolving international literature that examines minimum wage effects on labour market outcomes.

\begin{tabular}{lll}
\hline Article type: & research article \\
& minimum wage; construction sector; spatial heterogeneity; labour \\
Keywords: & market outcomes; Switzerland \\
JEL codes: & C33, J31, J38, J61 & \\
\hline Received: 24 February 2020 $\quad$ Revised: 27 May 2020 & Accepted: 18 June 2020 \\
\hline
\end{tabular}

\section{Suggested citation:}

Stricker, L., \& Baruffini, M. (2020). Impact of labour market liberalisation on minimum wage effects: The case of the construction sector in a small open economy. Entrepreneurial Business and Economics Review, 8(3), 155-174. https://doi.org/10.15678/EBER.2020.080309 


\section{INTRODUCTION}

The Swiss main construction sector is highly regulated compared to the remainder of the economy. A collective labour agreement (CLA) - Landesmantelvertrag (LMV) - ensures minimum wages and employment conditions for all construction employees. Moreover, the construction sector recruits a significant part of its low-skilled workforce abroad.

The objective of the article is to estimate the effects of the opening of the Swiss labour markets towards the European Union (EU) and the relative impact on the growth of the labour market outcomes (employment) compared to the variation of the minimum wage bite in the context of rising minimum wages over time. The bilateral application of the Free Movement of Persons Agreement (FZA) by the EU and the Swiss Confederation and the consequently higher worker mobility changed the way in which minimum wage floors affect the functioning of the Swiss construction labour market.

The treatment in this research will be measured regarding the effect that the minimum wage bite has on employment. The minimum wage bite is the quota of workers in this period earning below the minimum wage of the upcoming year. The source of the changes in the treatment variable derives from the rise of the minimum wage level for unskilled employees in the main construction sector. The external shock we want to analyse is the application of the FZA agreement, which impacts the relationship of the minimum wage bite and employment effects. The spatial unit of the study is the cantonal level (NUTS - 3). Furthermore, cantons are used to control for spatial heterogeneity.

Our findings show that because of the application of the FZA in June 2002, the growth rate of employment was lower than the minimum wage bite growth. Considering employment effects, the impact of changed minimum wage bites were different, depending on the chosen specification. The analysis is conducted using a base model and six variations of the model, including different controls and spillover effects of the economically interconnected cantons, defined as economic neighbours. The first four models control for different variables - economic structure, firm size, and wage dispersion - and all these variables are included in the last model. The last two models control for potential spillover effects of neighbouring cantons, including more or fewer control variables.

This paper makes two contributions to the literature. First, using both a panel data approach and an approach that includes neighbouring effects, we contribute to the evolving international literature that examines minimum wage effects on labour market outcomes. Second, we focus on the Swiss context, enriching the ongoing research on European cohesion policy. The studied labour market liberalisation focuses specifically on the construction industry, employing both low-wage and high-wage earners and a significant share of the foreign workforce.

We use nationally representative data from the Swiss Labour Force Survey (SLFS), ${ }^{1}$ conducted every year by the Swiss Federal Office of Statistics (FSO). This survey provides data on workers' characteristics, such as working hours, earned wages, working places, and sectors of activity. In addition to this database, information on annually valid minimum wage levels for unskilled employees in the construction sector was extracted from the LMV

${ }^{1}$ Swiss Labour Force Survey (SLSF) 1999-2016, source: BFS: Schweizerische Arbeitskräfteerhebung (SAKE). 
databases. These are published every year on a cantonal basis by the Swiss constructors' association (Baumeisterverband SBV).

Our analysis of the impacts of the FZA in the Swiss main construction sector is structured as follows. Section 2 reviews the literature concerning minimum wages and economic liberalisation. Section 3 introduces the institutional setting, describes the data, and our measures of minimum wages in Switzerland. Finally, it formalises the model and the variations. The results are discussed in Section 4, while Section 5 presents concluding remarks.

\section{LITERATURE REVIEW AND THEORY DEVELOPMENT}

This paper contributes to the recent literature, combining two different streams of research in a joint Difference-in-Difference (DiD) model. From the methodological viewpoint, we try to contribute to the broad DiD literature. We follow the approaches widely discussed by Abadie (2005) and Author (2003), but also the important application by Card (1992), which helps to refine the research strategy of the present work. Finally, we refer to the contribution of Bertrand et al. (2004) with important implications on the detailed empirical strategy. As a novelty, we analyse the impact of the labour market liberalisation in a classic minimum wage and employment effects model. For this aim, the following part tries to reappraise the existing literature in the two fields and to highlight the relevant parts for the analysis.

\section{Minimum Wage Bite and Wage Effects}

A broader literature refers to the impacts of minimum wages on the labour market, which has been extensively researched during the last decades. A review of the literature on this topic is in detail explained in the book of Cahuc et al. (2014).

From a theoretical viewpoint, minimum wages can have an effect in two ways: on the one hand, the introduction of minimum wages can lead to transitional labour market flows (Mortensen \& Pissarides, 1994) and job matches under a certain productivity level are destroyed. Moreover, the introduction of minimum wages may change the optimal combination of firm and worker characteristics.

On the other hand, the introduction of minimum wages may have an effect on equilibrium outcomes. If a minimum wage is above the reservation wage before its introduction, it simply deletes jobs. Moreover, if the minimum wage implies a lower level of salaries, it leads to a lower level of direct job-to-job transitions (van den Berg \& Ridder, 1998). Finally, the effect depends on the elasticities of job search and vacancy creation. Therefore, the final effect is not clear ex ante, hence there are several empirical approaches.

Vom Berge and Frings (2019) model the effects of a minimum wage introduction in the several districts of the German economy. Their benefits are to include spatial spillover effects and use the minimum wage bite as treatment variable; our model considers both factors in a similar way.

Recent literature, for example for Canada (Brochu \& Green, 2013), Portugal (Portugal \& Cardoso, 2006), the United States of America (Dube et al., 2010), and Germany (Bachman et al., 2012), generally states that the employment effects of minimum wages are probably small or inexistent for total employment. Only the weaker part of 
workers could be affected, justifying the focus on bite in research (Kampelmann, Garnero, \& Rycx, 2013). Consequently, the minimum wage bite - the bite calculated on the next year's minimum wage - is an adequate measure because it best captures the marginal employees that are at highest risk of unemployment.

In their analysis of the impact of minimum wages on employment and inequality, Dolton et al. (2012) rely on the minimum wage bite as a variable of analysis: they illustrate their reasoning and justification for the adoption of the minimum wage bite in the analysis. Their explanations, using a structural econometric model, consist of two equations already previously suggested by Card (1992) and Stewart (2002). The first of the two equations assumes the concept of labour demand. It describes the move of the employment rate $\left(\Delta E_{j}\right)$ along the labour curve with a set wage level. In other words, employment is defined as a function of wage. In the second equation, a form of identity - the wage variation - is a function of the proportion of low-paid workers $\left(P_{j}\right)$. Substituting the second equation in the labour demand equation, the equation changes as follows (Dolton, 2012):

$$
\Delta E_{j}=\gamma_{0}+\eta \alpha_{1}+\beta P_{j}+\varepsilon_{j}
$$

in which $\beta=\eta \lambda$, and $\lambda$ is assumed to be positive, implying that $\beta$ has the same sign as $\eta$, and according to economic theory, both are negative. In other words, the higher proportion of low-paid workers, in our case contributing to a higher bite, would result in a negative variation of employment (Dolton, 2012).

Steward (2002) sets the precondition for identification of this model as the proportion of low-paid workers $\left(P_{j}\right)$ being a predetermined instrument for the endogenous wage change. In the next section we discuss this precondition, which implies that an endogenous variation of the bite through variation of the workforce composition can be neglected. In our research, the bite is consequently defined to be affected by changing minimum wage policy and economic conditions, but not through more than proportional growth of low-wage workforce.

\section{Effects of Labour Market Liberalisation}

Favre (2011) follows the approach of analysing the competition among workers along the entire wage distribution, as proposed by Dustmann et al. (2013), and shows that the competition between natives and immigrants is at the two tails of the wage distribution. This approach is in contrast to the earlier literature in the field that presents the correlation of the mean wage variation in response to the market liberalisation across spatial units. Data from years preceding 2011 provide evidence about the changes in the education level of immigrants in Switzerland. Due to the labour market liberalisation between Switzerland and the European Union, highly skilled workers also started to be attracted. This trend is also emerging in the wage distribution, in which immigrants have been recently overrepresented in the low and high wage classes (Favre, 2011).

Our analysis, focusing on the correlation between average wages and employment with the minimum wage bite growth, follows the standard literature.

Nevertheless, the insights gained from the work of Favre (2011) are useful for the understanding and interpretation of the results. A further distortion is that not each region is similarly attractive to immigrants, but they tend to allocate in areas with an already high presence of other immigrants of their nationality. This might attract more immigrants from countries with languages different from the Swiss national languages. Moreover, a second 
issue is the inter-regional mobility of workers, which can cause employees to move from one place to another with less competition in earnings.

A work published by Gilpin et al. (2006) focuses on the effects of the European free movement of workers agreement on the UK labour market. The policy was implemented in a time of rising unemployment in 2005, and therefore, this was dealt with as one of the contributors to unemployment. The research finds no statistical evidence that the agreement was a contributor to the higher unemployment.

Focusing on the wage effects, the research takes into consideration the growth rate of the Average Earnings Index. For this comparison, there is low evidence of a fall in nominal wage growth in reaction to market liberalisation. No discontinuity in the wage growth rate was observed, and even for the missing counterfactual, it was not possible to find a significant effect of immigration on wages (Gilpin, Henty, Lemos, Portes, \& Bullen, 2006).

Our hypothesis is that - as a consequence of the liberalisation of the Swiss labour market - the median wage of the common space falls with respect to the minimum wages of construction. According to previous studies discussed by Neumark and Wascher (2008), this would lead to stronger minimum wage effects and put pressure on employment in this industry.

\section{MATERIAL AND METHODS}

\section{The Swiss Construction Sector}

According to the most recent data from 2016, the construction sector achieved a net product of 33.71 billion (bn) CHF overall. Compared to the nominal Swiss gross domestic product (GDP) of 650.11 bn CHF, this corresponds to $5.15 \%$ of the GDP. Regarding achieved revenues in 2016, civil engineering with 10.17 bn CHF slightly exceeded structural engineering, which reached revenues of $9.80 \mathrm{bn} \mathrm{CHF}$. The entire construction sector employed 80700 workers in September 2016, of which 65400 were workers on the construction side, 10800 technical and service employees and 4600 trainees. The labour force was composed of $56 \%$ of foreigners (45 300 employees), compared to 35400 native workers. The average wage achieved across the entire construction sector amounted to $5765 \mathrm{CHF}$ per month across all wage classes (Baumeisterverband, 2016).

Concerning the percentage of GDP, the expenses for construction decreased over the years, reaching a minimum in 2008 as a consequence of the financial crisis, and registered a smooth increase since then. In contrast, the net nominal product of the sector increased overall, except for an expected slight reduction for the last year considered in the data to be 2016 (Baumeisterverband, 2016).

It is essential to understand how the share of expenses on construction change in Switzerland. One point to focus on is undoubtedly workforce productivity. Increasing productivity means that the output costs can be reduced, workers' wages can be increased, or the firm's profits can grow. In a competitive sector such as main construction, the first two alternatives are the most plausible. According to historical data (Figure 1), (real) labour productivity in the construction sector was increasing in the 1980s, and then, starting in the 1990s, no significant increments were registered.

Keeping in mind the three alternative effects of increasing productivity, we should focus on the growing productivity of the workforce as the primary driver of wage growth. 
The trend over the past couple of years shows that the wages of employees in construction industry continuously grew over time. They also grew in real terms, compared to the inflation index, as shown in Figure 2 below. Since 2008, the wages of construction site employees - covered by the national collective wage agreement Landesmantelvertrag (LMV) - which will be the focus of this work, grew in real terms by $8.5 \%$ on average. Only supervisors' real wages grew more than that (Baumeisterverband, 2016).

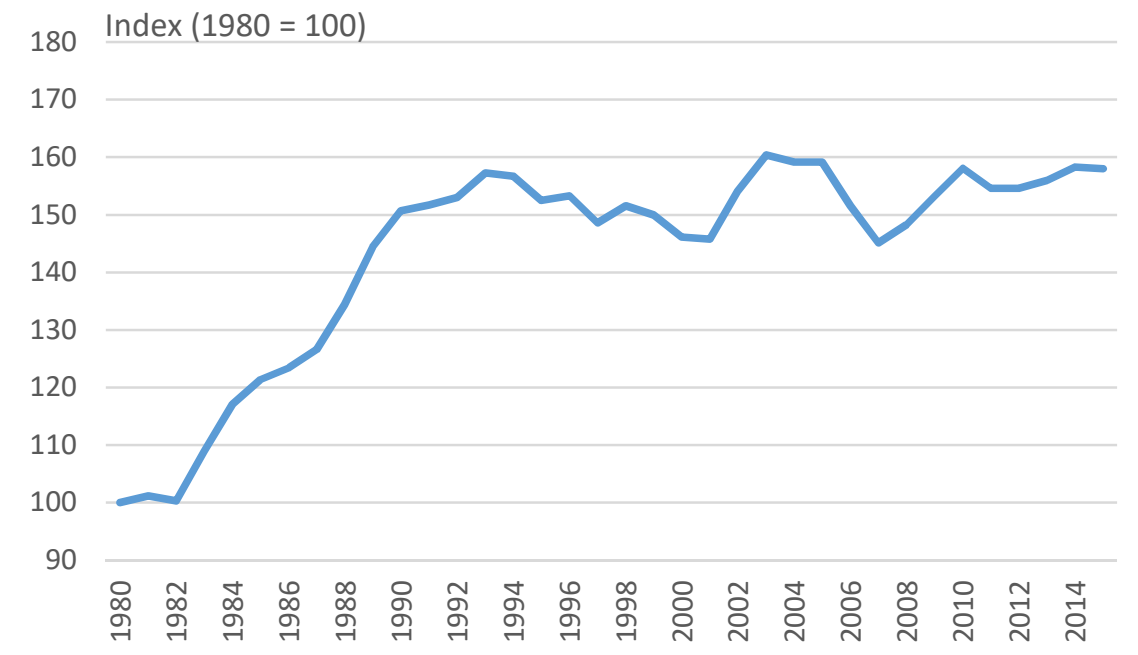

Figure 1. Labour productivity (real in full-time equivalents) in the Swiss construction sector Source: data from BAK Basel: labour productivity in construction.

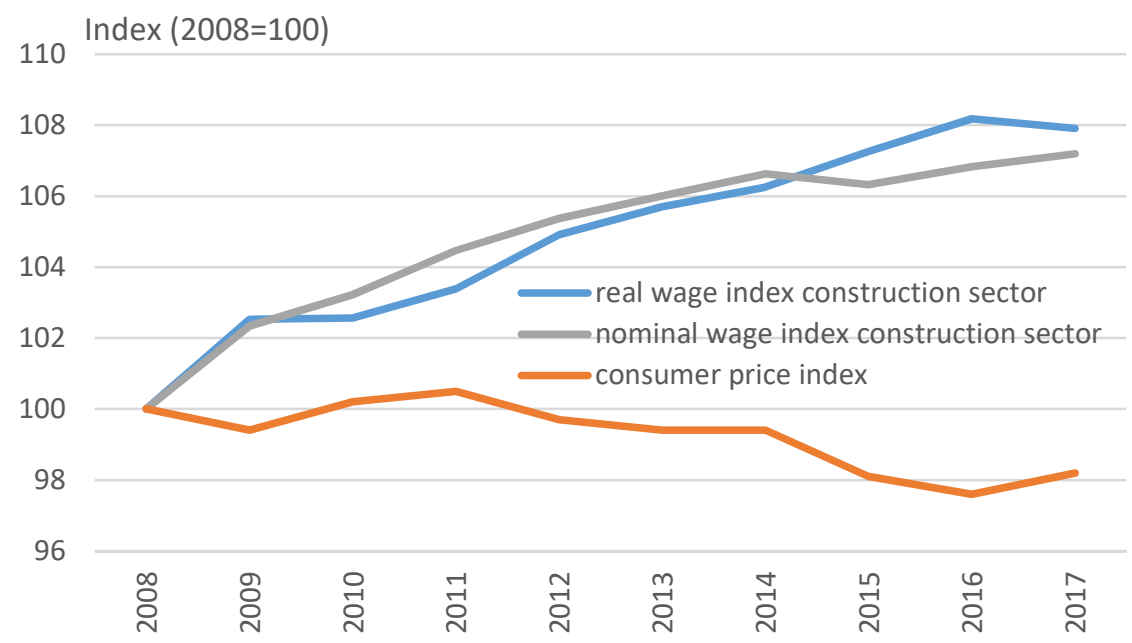

Figure 2. Wages in the main construction sector and inflation Source: Swiss Federal Office of Statistics (SFO): real and nominal wages in construction and consumer price index. 
A further possibility for a firm facing higher labour costs is to forward the additional expenses directly to the consumer market. Giupponi and Machin (2018) checked for this possibility in their study on minimum wages in the care home industry. Figure 3 compares the indexed growth of the prices of the construction industry and the indexed growth of the minimum wages in the sector. We can divide the period into two parts. The first covers the years preceding 2008 and presents a significant relative growth of minimum wages, which is linked to growing construction prices. In the second period of the most recent years, construction prices stagnated on a stable level and, therefore, entailed a limited capacity to absorb higher wage costs, which were passed on to consumers. The evidence from this data comparison suggests a partial absorption of the wage effect on employment and a lower employment effect than would occur in the absence of this absorption.

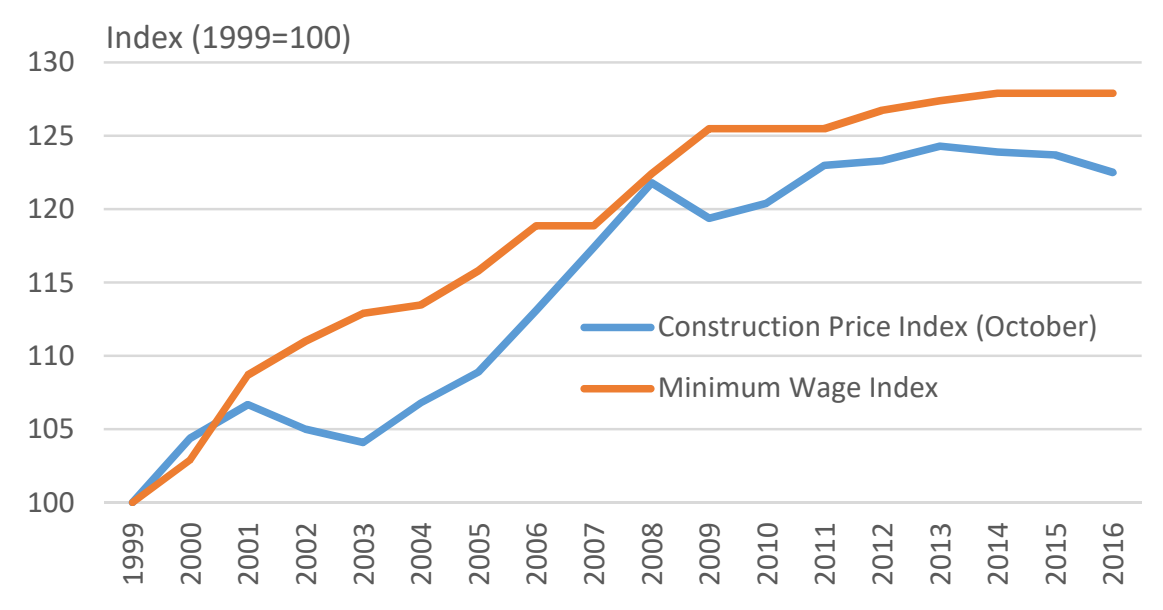

Figure 3. Minimum wage index in the construction sector and construction price index (month of October)

Source: Data from the Swiss Federal Office of Statistics (SFO): construction price index and minimum wage data from the collective labour agreements of the Swiss constructors' association (Baumeisterverband).

Again considering the labour market outcomes, the hypothetically higher productivity of the workforce could be translated into a reduced requirement for the workforce to produce the same amount of output. Hence, the next focus is on the number of employees in construction over time. Figure 4 below highlights the variability of the workforce in the Swiss main construction sector. The sector registered a drop in employment as a consequence of the real-estate bubble in the 1990s and grew afterwards until 2014. In the last few years, employment fell again. Most of the growth was registered in the finishing construction segment, a part of the sector that does not apply minimum wages as proposed in the LMV. The main construction sector grew by less (Baumeisterverband, 2016).

The main focus of this study is on the minimum wage variation as a result of higher pressure on the labour market. We need to limit the effect of a heterogeneous growth of the workforce in the sector that could endogenously affect the variation of the minimum wage bite. Therefore, we choose to analyse the growth of the low-wage and high-wage workforce compared to the total growth of the workforce in the construction sector in each of the Swiss greater regions (NUTS-2). Figure 5 shows these trends for Switzerland at 
the national level. Over the observed years, total employment in the construction sector grew. Moreover, the data highlight that this growth was mainly due to the evolution in the high-earning share of the workforce, while the number of low-wage employees remained stable in the same period. This trend is valid for each of the greater regions of Switzerland. We can exclude from this viewpoint a rising minimum wage bite as a consequence of a more than proportional growth of employment in the lower part of the wage distribution. In this case, variations in the minimum wage bite must result from the exogenous variation of minimum wage level and the changing economic environment and conditions.

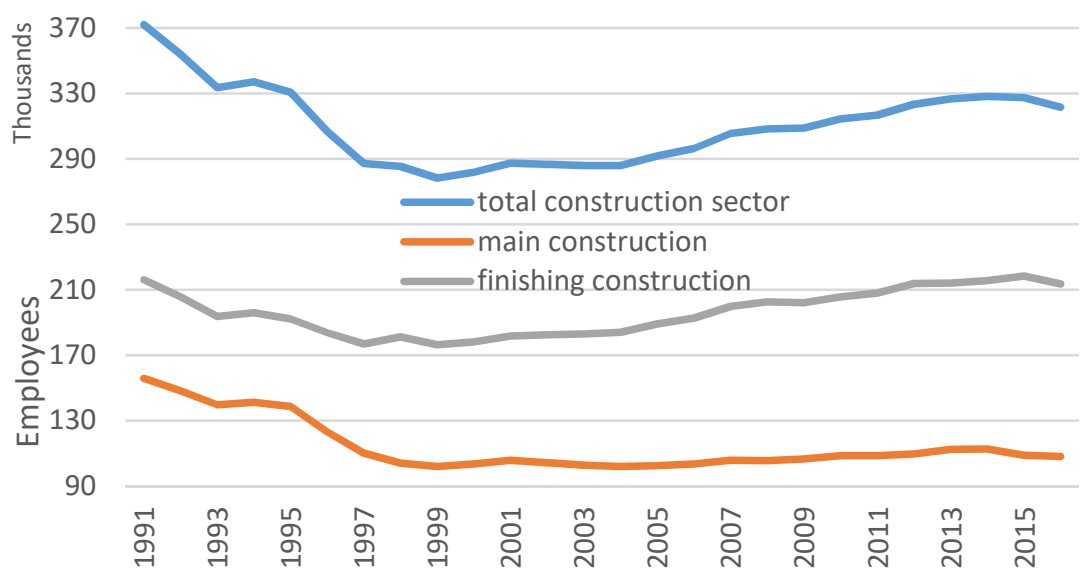

Figure 4. Employment (full-time equivalents) in the construction sector in the third quarter of the year

Source: Data from Swiss Federal Office of Statistics (SFO): Job Statistics.

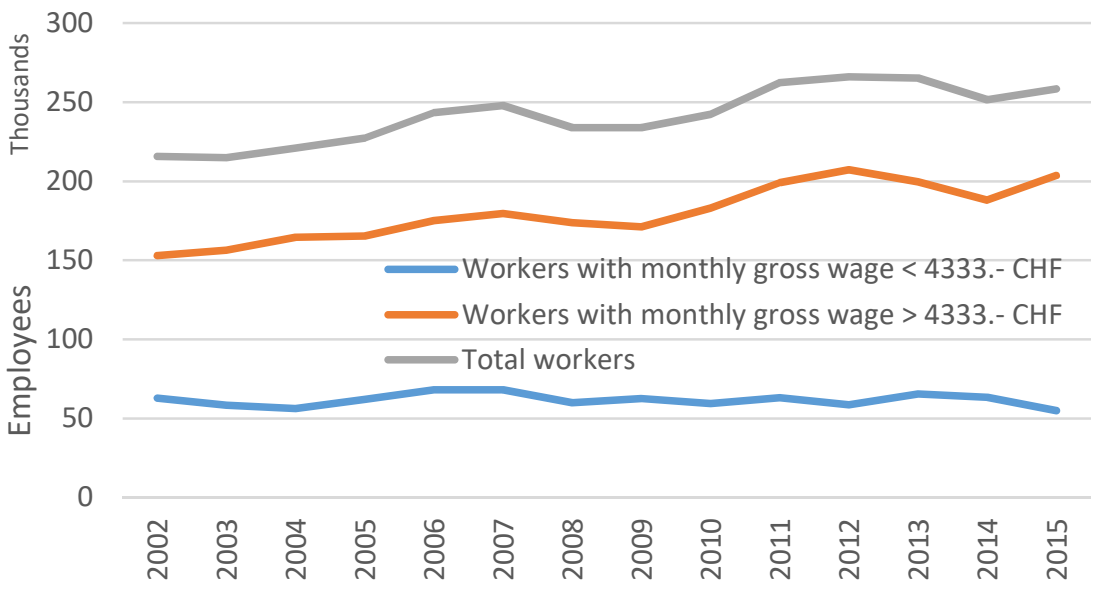

Figure 5. Employment in the construction sector in Switzerland, by wage classes Source: Data from Swiss Federal Office of Statistics (SFO): Swiss Labour Force Survey (SLFS). 
A crucial last factor is the educational level of employees in the main construction sector because the lowest possible minimum wage applied to unskilled workers is the point of reference for this study. Therefore, unskilled workers are potentially most affected by varying minimum wages, particularly if the focus is on the lowest wage group. The increasing number of skilled workers in the labour force is due to the increasing complexity of construction sites. Many tasks require specialised skills to keep up with technological progress.

Moreover, in general, the quota of unskilled workers on the Swiss labour market is decreasing. Only the share of supervisors is nearly unchanged over the years. The exclusion of supervisors in the general trend towards higher-skilled workers is mainly because they execute jobs that are different from those of the two other groups of workers (office work rather than jobs on the construction site) (Baumeisterverband, 2016).

\section{Free Movement of Persons Agreement (FZA) Switzerland - EU}

In 1999, Switzerland signed bilateral agreements with the European authorities and countries, and the population approved them in May 2000. According to the bilateral agreement on the Free Movement of Persons (FZA), all citizens of European countries have the right to freely choose their location of residence within the zone of all contractual partners. Additional components of the agreement were the coordination of national social security systems and the mutual recognition of foreign professional diplomas.

The agreement was adopted gradually during a transition phase, and instruments such as priority to natives and contingency systems could still be applied unilaterally. These measures were also known as "valve clauses" to ensure a gradual and controlled merger of labour markets. For the original 15 EU nations, Malta and Cyprus, the agreement was to begin on the 1st of June, 2002, and entered in full force in 2007, after which it was no longer possible to apply "valve clauses" (EDA, 2017).

In 2007, the border zones of Switzerland were abolished, and through this, a further limitation to labour mobility was removed (Verein-Grenzgänger, 2013). Afterwards, even citizens from non-neighbouring countries could work in Switzerland with a cross-border commuter permit. This further policy change caused a second wave (after 2001/2002) of strong relative growth in the number of cross-border commuters in Switzerland.

To reduce violations against Swiss wage and labour conditions, supporting measures were applied in 2004. These measures made it possible to ensure that employers meet the conditions foreseen in CLAs and that Foreign Service providers maintain guidelines contained in the employee secondment law. Tripartite commissions are in charge of controlling and checking the application of these measures. The commissions are composed of representatives from public authorities, employers, and labour unions. Their main task is to check for compliance with regular and CLA norms. The employment secondment law has been adapted continuously to meet the requirements of a changing environment and the growing zone of application of the Free Movement of Persons Agreement. Hence, the most recent refinements were taken in the inclusion phase when Romania and Bulgaria entered the agreement (EDA, 2017). 


\section{Dataset}

This study is based on data from the Swiss Labour Force Survey (SLFS), along with supplementary and specific data about minimum wage levels for main construction workers in Switzerland; in addition, data from the Swiss Federal Office of Statistics (SFO) were used to define spatial parameters and regional peculiarities.

The first of the two primary data sources, the SLFS, is annually conducted by the SFO and has interviewed up to 105000 subjects since 1991. The questionnaires include several features around the topics of employment, unemployment, and the educational and professional background of interviewees. Further questions cover geographic and sociodemographic issues. Social security, education, and migration topics complete the survey. For this research, the variables that identify the sector and industry of activity of an employee, but also the identification of the geographical unit - Switzerland's 26 cantons - are of particular interest. The core element for the aim of this research is the wages associated with the share of workers employed in the main construction sector. However, those wages are not revealed uniquely and therefore need to be standardised to guarantee comparability. All wages are counted as annual net wages to compare employees with salaries on an hourly basis and part-time employees with full-time wage earners.

The process of wage standardisation follows three principles, concerning the working hours per worker, the contributions of unemployment insurance (ALV) and the pension fund contributions. This SLFS microdata in the end was then aggregated into a cantonal panel data set, including both wage and employment indicators divided by year and cantons.

Moreover, taking into consideration the minimum wage for the main construction sector in accordance with the collective wage agreement (LMV), it is possible to draw a local minimum wage that formulates the reference independently of qualifications. The first national agreement was accorded during 1998 and officially enacted on the $1^{\text {st }}$ of January, 1999; for this reason, construction minimum wages exist since then. These wages are divided into three different categories that take into account spatial heterogeneity. For cantons split up in two different wage categories (Bern, Schwyz, St. Gallen, Solothurn) - following a precautionary principle - the lower of the two included levels was considered as a reference. The provided minimum wages are standardised according to the personal characteristics on an annual net level, following the same principles described above and according to individual characteristics, determined in this case by the spatial association with the canton of activity.

Finally, the merging of the two databases, including observations from years 19992016, allows for the construction of the final panel dataset that includes the determinants of all 26 Swiss cantons over a period of 17 years. The main variables for this panel define the economic structure, the importance of the construction sector in a particular region, and the workplace distribution among different economic sectors. The primary independent variable includes a reflection of the wage structure prevailing in the main construction sector. We focus on the effects of changing wage policies in the labour market, which are changing levels of employment in the sector. This issue is discussed with a particular focus on the theoretical part of this work. The variables consider the main construction sector's changing wage structure and the employment effect, formalised concerning a relative change in employment on a logarithmic scale. The second of these two variables, including 
all others except the main construction sector, is constructed similarly and then included as a further independent variable in the model.

When choosing the measure to analyse the effects of a given wage floor, researchers frequently have to deal with the minimum wage bite. This section is devoted to the explanations that favour the choice of this measure to evaluate the impacts of defined wage policies.

As explained in detail by Kampelmann, Garnero, and Rycx (2013), the Kaitz index - the relation of minimum wages to the overall wage distribution - is not the right measure for all issues, especially not for studying the impact of minimum wage policies. The minimum wage bite is the better choice for this aim. It focuses on a particular part of the wage distribution, namely the employees earning wages at and below the minimum wage threshold. An interesting application of the bite consists of focusing on the effects of an increased minimum wage in a defined sector. Following the neoclassical models for the labour market, this would imply that workers in the minimum wage bite would lose their job if they were not able to increase their marginal productivity above the new wage. According to this framework, the variation of the bite is a measure that helps understand the reaction of firms. They still have the possibility to pass the higher production costs to the customer or to reduce their actual profits. Alternatively, as previously mentioned, the productivity of employees can improve, e.g. by taking additional courses or reviewing the organisational structure of firms (Kampelmann, Garnero, \& Rycx, 2013).

On average, across all observed years, $10 \%$ of employees are employed on a marginal wage basis: this means that they earn salaries that would be below the minimum wage the upcoming year (the minimum wage bite). This distribution is not homogeneous across the 26 cantons and is not persistent over time.

Each of the 26 cantons is grouped in one of the three "regions" that define the level of wages that apply to all employees of the sector (Figure 6). The highest levels are applied in the two cantons of Geneva and Vaud in the western part, but also the two cantons of Basel-Stadt and Basel-Landschaft. The lowest levels are applied among the cantons situated in the south-eastern part of Switzerland, Schaffhausen and Bern.

The evolution of the minimum wage levels in absolute terms for the three abovementioned regions is presented below in Figure 7 for the entire period of analysis. The colours of lines in Figure 7 correspond to the three regions on the map in Figure 6, with the darkest line applying the highest minimum wage level and the lightest one applying the lowest possible level in the region.

The average annual net wage of employees in the main construction sector in Switzerland is $72086 \mathrm{CHF}$, and it is $95560 \mathrm{CHF}$ for the other sectors in 2010. The share of employees in the main construction sector represents, on average, $3.5 \%$ of total employment. These values also change across cantons.

A factor that might influence the wage differentials across cantons is the different relative importance of the construction sector in the regions. The higher concentration of construction sector can be explained in the less densely populated regions, as there is a relatively high requirement for civil engineering to maintain traffic and public infrastructure. Furthermore, regions with a low presence of workplaces in other industries and regions without any large centre offering services show a higher share of construction sector in the regional economy. 


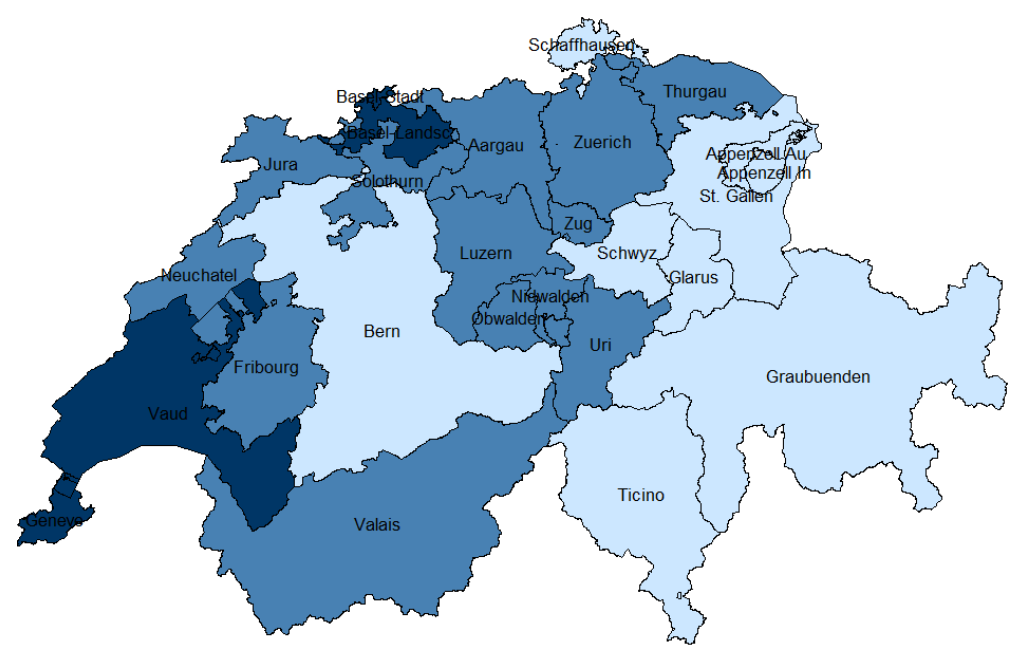

Figure 6. Regions with different minimum wage levels according to the collective labour agreement

Source: own illustration based on minimum wage data from the collective labour agreements of the Swiss constructors' association (Baumeisterverband).

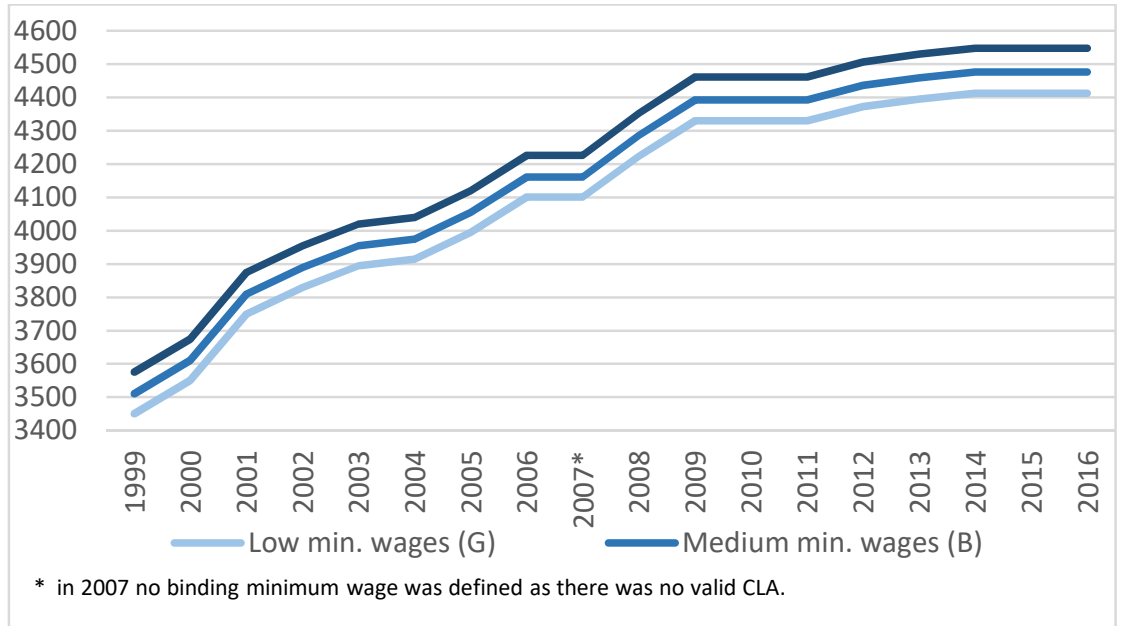

Figure 7. Monthly gross minimum wages for unskilled workers in the construction sector in 1999-2016, for each of the three regional minimum wage levels

Source: own elaboration based on minimum wage data from the collective labour agreements of the Swiss constructors' association (Baumeisterverband).

\section{Method and Empirical Strategy}

The basis for the construction of our model is the approach proposed by vom Berge and Frings (2019), who focus on the introduction of a minimum wage in Germany and its effects on the labour markets, distinctly for Western and Eastern Germany. They combine 
the panel approach of Neumark and Wascher (1992) with the approach of applying minimum wage bites, as in Card (1992). According to vom Berge and Frings (2019), the posttreatment effects are different from the effects in the period preceding the exogenous shock. In their paper, they use the introduction of the minimum wage in 1997 in Germany. The cut-off for the present study is the application of the Free Movement of Persons Agreement in Switzerland in 2002 with the original 15 EU countries. Differential trends of the minimum wage effects are captured analogously in the pre-treatment period following Dolton, Bondibene, and Wadsworth's (2010) study in the UK.

For the first estimation, we followed vom Berge and Frings (2019) but varied and adapted the specifications to explain the various effects of the policy adaptation on the labour market outcome. We further included a continuous time trend instead of time fixed effects, according to the research focus and because the impact of policy application happens across a more extended period after the policy introduction and concerns a smooth application of the labour market liberalisation, rather than a particular impact in time. This choice is based on the assumption that the effect we estimate is adopted smoothly and not as a shock in a specific year.

The difference between the two models applied is that the first one considers the local economy in a box, while the second analysis includes spatial spillover effects from interconnected cantons. Both models have been tested for consistency, leaving out some of the included control variables.

The first part considers control variables - specific to each canton - without taking into account the interconnectedness of regional labour markets within the same country. The model in specification 5 in the results table includes $y_{i t+1}$, which describes the employment growth in region $i$ (in our case: cantons) in the time from $t$ to $t+1$, while $d$ is the indicator for the post-treatment effect; in this case, the introduction of the minimum wage. Similar to vom Berge and Frings (2019) we chose to use the growth of employment as dependent variable instead of levels since we are interested in signs of employment variation and not in describing what actually defines the stock of employees. $\beta^{D}$ captures the treatment effect on the minimum wage. Instead, $x_{i t}$ would be the mean employment or wage growth in other industries, except for all construction sectors. $\mu_{i}$ represents canton fixed effects, while $\lambda t-$ a continuous time trend. Furthermore, the variable $q_{i t}$ represents the ratio of secondary sector workplaces compared to third sector workplaces, and the variable $s_{i t}$ is constructed as the number of firms with 50 or more employees divided by the number of firms with less than 50 employees for every canton in every year. Finally, control variable $r_{i t}$ is constructed as the coefficient of the $25 \%$ quantile divided by the $75 \%$ quantile of wage distribution in year $t$ and canton $i$. We should remember that this control variable is calculated for the analysed year $t$, differently from the computation of the minimum wage bite, which we calculate based on the wage distribution of the upcoming year $t+1$ and, therefore, it does not describe the same data. This last control measures the wage dispersion in the construction industry. We choose to include those variables in order to capture the peculiarities and to describe the structure of the local economies in individual cantons.

$$
\begin{gathered}
\Delta \ln y_{i t+1}=b_{i t} \alpha^{D}+\left(d \times b_{i t}\right) \beta^{D}+\Delta \ln x_{i t} \gamma^{D}+q_{i t} \delta+s_{i t} \psi+r_{i t} \phi+\mu_{i}+ \\
+\lambda t+\epsilon_{i t}
\end{gathered}
$$

In our study, the focus is on the employment effects of labour market liberalisation and not on wage redistribution, as in vom Berge and Frings (2019). The formulation foc- 
uses on employment effects and the reduction of workplaces in response to higher minimum wages, again using the pre-FZA period for calibration and the post-treatment period to focus on this problem.

In addition to this model, four variations (specifications (1)-(4)) - each considering only some of the variables and controls - are applied to check for the consistency of results in specification (5), considering the cantons as single, closed entities.

The second model design, unlike the first one, includes the possibility that variations in interconnected local labour markets affect neighbouring cantons. Borders among cantons are open and depend on the geographic position; mobility is rather high among some of them. It could therefore be a problem to analyse the effects keeping the cantons as separate units without taking into account the trends of their neighbours. In addition to the already included variables, this specification includes average values of independent variables from the surrounding cantons. We distinguish direct effects $(D)$ - or the variable characterising the trend and situation in the analysed canton - and indirect effects $(I)$ that capture the impact of the average of variables of all cantons as economically interconnected with the analysed one. The two variables $b_{i t}$ and $x_{i t}$ are averaged for all the neighbouring cantons $(N)$ as a weighted average and included in the regression. Weights $f_{j i}$ are constructed as the share of all inbound commuters towards canton $i$ who reside in canton $j$; these data come from MZMV $2015^{2}$ and remain fixed across the analysed period. We chose to include this kind of spillover effects for the present case rather than spatial econometrics since Switzerland has a particular topography and the constructed matrix of commuter streams is more suitable to account for the relative interdependence of local labour markets among the cantons. In this definition, every canton is a neighbour of all the other cantons, and the larger the commuter stream is the "closer" these regions are by definition, independent of their geographical position. Adapting this as the baseline model, the following regression - specification 7 in the results table - can be written as follows:

$$
\begin{gathered}
\Delta \ln y_{i t+1}=b_{i t} \alpha^{D}+\left(d \times b_{i t}\right) \beta^{D}+\Delta \ln x_{i t} \gamma^{D}+{\overline{b_{l t}}}^{N} \alpha^{I}+\left(d \times{\overline{b_{l t}}}^{N}\right) \beta^{I} \\
+\Delta \ln \bar{x}_{l t}^{N} \gamma^{I}+q_{i t} \delta+s_{i t} \psi+r_{i t} \phi+\mu_{i}+\lambda t+\epsilon_{i t} \\
\text { in which } \quad{\overline{b_{l t}}}^{N}=\sum_{j=1}^{26} f_{j i} * b_{j t} \quad \text { and } \quad \Delta \ln {\overline{x_{l t}}}^{N}=\sum_{j=1}^{26} f_{j i} * \Delta \ln x_{j t}
\end{gathered}
$$

Similar to the baseline model, a variation of this model is set up - specification (6) in the results table - again by excluding additional control variables to test specification (7) results.

\section{RESULTS AND DISCUSSION}

In Table 1, we report the results for the seven conducted scenarios formally introduced in the preceding section. We further include a continuous time variable $(\lambda t)$ to control for time-specific trends. A continuous time variable is the best choice for our problem set, because we are not interested in a significant event with a specific shock in one year but aim to control for the trend of the time component itself.

The results suggest a positive relationship across specifications (1) to (5) for the minimum wage bite $\left(\alpha^{D}\right)$ and the next year's growth of employment. No significant coefficients were obtained for models (6) and (7). Therefore, if we observe a growing minimum wage

\footnotetext{
${ }^{2}$ Mobility and Transport Microcensus (MZMV) 2015, source: BFS/ARE: Mikrozensus Mobilität und Verkehr.
} 
bite - in other words, a larger share of employees being paid a wage lower than the next year's minimum wage - we will still observe growing employment. With the introduction of the FZA agreement, we include a second time the minimum wage variable as a posttreatment variable $\left(\beta^{D}\right)$. What we observe across specifications (1) to (5) is a negative sign of the treatment effect. This means that with a growing minimum wage bite in the period following the introduction of the FZA agreement, employment does not grow further. Considering the following variables, we notice that the construction industry follows this trend in employment growth but less intensely than the remainder of the economy $\left(\gamma^{D}\right)$. This is true for all specifications, and the results are significant at the $1 \%$ level. For specifications $(2),(5)$, and (7), we include a variable controlling for the economic structure $(\delta)$. The coefficients imply a negative impact on employment growth in construction. The more extensive share of secondary sector workplaces concerns the ones in the service sector. In specifications (3), (5), and (7), we include a variable $\psi$ indicating the quotient of large firms (50 or more employees) and small firms (less than 50 employees) in the construction industry. The results suggest a positive effect on employment growth if the share of large firms increases. These results are significant at the $1 \%$ level for specification (7) and at the $10 \%$ level for (5) but are not statistically significant for specification (3).

The last of the included variables, wage dispersion $(\phi)$, does not provide results at a significance level of $10 \%$ or lower. The sign of coefficient suggests that a lower dispersion of wages would be connected to higher growth of employment. Therefore, less inequality of wages in construction would promote employment growth. The remainder of variables are the weighted averages of previously mentioned controls for neighbouring cantons. Considering coefficients $\alpha^{I}$ and $\beta^{I}$ - neither result is significant at a level lower than $10 \%$ - for the trends in neighbouring cantons, the sign is identical to the direct effect. Growing minimum wage bites in the pre-treatment period in the neighbouring cantons are connected to higher growth in employment in the considered cantons; similarly, the direct effect diminishes when applying the post-treatment variable for the neighbouring cantons as well (results not significant). In the end, $\gamma^{I}$ establish a positive relationship between the growth of employment in the neighbours' economy - excluding the construction industry - and employment growth in construction industry of the considered canton.

Summarising these results, we can observe some important points. For the first five specifications (1) to (5), the minimum wage bite variation significantly contributes to the variation of employment in the construction sector. This is not true for specifications (6) and (7), in which we do not look at single cantons as a box but include spillover effects. Apparently, in those specifications, the variation of employment in construction is guided by the variation of non-construction employment in the canton of analysis and the neighbouring cantons, while in specification (7) the variation is additionally guided by coefficients $(\delta)$ and $(\psi)$. Therefore, we can say that the trends of employment variation in the remainder of domestic economy and in interconnected cantons absorb the employment effect of minimum wage bite variation. To conclude, we should keep in mind that the mechanisms change in the two different analyses. First, we identify a significant effect of minimum wage bite variation on construction employment and a significant treatment effect of policy change when looking at single cantons. Outside the box, both before and after the labour market liberalisation, employment effects are closely related to economic trends and structural indicators of the local economy and the corresponding spillovers from all interconnected cantons. 
Table 1. Effects of the FZA on employment in the main construction sector

\begin{tabular}{|c|c|c|c|c|c|c|c|c|}
\hline Specification number & & (1) & (2) & (3) & (4) & (5) & (6) & (7) \\
\hline VARIABLES & & $\begin{array}{c}\text { Base- } \\
\text { line } \\
\text { Model }\end{array}$ & $\begin{array}{c}\text { Baseline } \\
\text { Model } \\
\text { with Econ. } \\
\text { Structure } \\
\text { var. }\end{array}$ & $\begin{array}{c}\text { Baseline } \\
\text { Model } \\
\text { with Firm } \\
\text { Size Index }\end{array}$ & $\begin{array}{l}\text { Baseline } \\
\text { Model with } \\
\text { Wage Dis- } \\
\text { persion }\end{array}$ & $\begin{array}{c}\text { Baseline } \\
\text { Model } \\
\text { with all } \\
\text { Controls }\end{array}$ & $\begin{array}{c}\text { Neigh- } \\
\text { bour } \\
\text { Can- } \\
\text { tons } \\
\text { only }\end{array}$ & $\begin{array}{l}\text { Neigh- } \\
\text { bour } \\
\text { Cantons } \\
\text { and all } \\
\text { Controls }\end{array}$ \\
\hline \multirow[t]{2}{*}{ Minimum wage bite } & $\alpha^{D}$ & $1.38^{* *}$ & $1.38 * * *$ & $1.41^{* *}$ & $1.38 * *$ & $1.47 * * *$ & 0.69 & 0.82 \\
\hline & & {$[0.53]$} & [0.49] & {$[0.54]$} & [0.53] & [0.48] & [0.57] & [0.51] \\
\hline \multirow[t]{2}{*}{$\begin{array}{l}\text { TE Minimum wage } \\
\text { bite }\end{array}$} & $\beta^{D}$ & $-1.43 * *$ & $-1.37 * * *$ & $-1.49 * *$ & $-1.43 * * *$ & $-1.50 * * *$ & -0.57 & -0.73 \\
\hline & & [0.51] & [0.47] & [0.54] & [0.51] & [0.48] & [0.55] & [0.51] \\
\hline \multirow[t]{2}{*}{$\begin{array}{l}\text { Non-construction em- } \\
\text { ployment differential }\end{array}$} & $\gamma^{D}$ & $0.46 * * *$ & $0.41 * * *$ & $0.46 * * *$ & $0.46 * * *$ & $0.41 * * *$ & $0.37 * * *$ & $0.34 * * *$ \\
\hline & & [0.08] & {$[0.08]$} & {$[0.08]$} & [0.07] & [0.08] & [0.07] & {$[0.07]$} \\
\hline \multirow[t]{2}{*}{$\begin{array}{l}\text { Share of secondary } \\
\text { sector workplaces }\end{array}$} & $\delta$ & & $-0.82 * * *$ & & & $-1.04 * * *$ & & $-1.01 * * *$ \\
\hline & & & [0.27] & & & [0.27] & & [0.27] \\
\hline \multirow[t]{2}{*}{ Firm size index } & $\psi$ & & & 0.18 & & $0.46^{*}$ & & $0.64^{* * *}$ \\
\hline & & & & [0.25] & & [0.23] & & {$[0.20]$} \\
\hline \multirow[t]{2}{*}{$\begin{array}{l}\text { Wage dispersion in- } \\
\text { dex }\end{array}$} & $\phi$ & & & & -0.82 & -0.25 & & 0.42 \\
\hline & & & & & [0.89] & [0.84] & & [0.77] \\
\hline \multirow[t]{2}{*}{$\begin{array}{l}\text { Neighbour's min. } \\
\text { wage bite }\end{array}$} & $\alpha^{I}$ & & & & & & 0.85 & 0.78 \\
\hline & & & & & & & [0.83] & [0.83] \\
\hline \multirow[t]{2}{*}{$\begin{array}{l}\text { Neighbour's TE min. } \\
\text { wage bite }\end{array}$} & $\beta^{I}$ & & & & & & -0.46 & -0.34 \\
\hline & & & & & & & {$[0.76]$} & [0.77] \\
\hline \multirow[t]{2}{*}{$\begin{array}{l}\text { Neighbour's non-con- } \\
\text { str. employment diff. }\end{array}$} & $\gamma^{I}$ & & & & & & $0.74 * * *$ & $0.76 * * *$ \\
\hline & & & & & & & [0.18] & {$[0.18]$} \\
\hline \multirow[t]{2}{*}{ YEAR } & $\lambda t$ & $-0.01 * * *$ & $-0.02 * * *$ & $-0.01 * * *$ & $-0.01 * * *$ & $-0.02 * * *$ & -0.00 & $-0.01 * * *$ \\
\hline & & {$[0.00]$} & {$[0.00]$} & {$[0.00]$} & {$[0.00]$} & {$[0.00]$} & {$[0.00]$} & {$[0.00]$} \\
\hline \multirow[t]{2}{*}{ Constant } & & $25.68 * * *$ & $33.38 * * *$ & $27.22 * * *$ & $28.79 * * *$ & $40.32 * * *$ & 5.70 & $19.18 * * *$ \\
\hline & & [7.34] & [6.79] & [6.74] & [7.97] & [6.69] & {$[6.81]$} & [6.37] \\
\hline Observations & & 409 & 409 & 409 & 409 & 409 & 409 & 409 \\
\hline R-squared & & 0.178 & 0.196 & 0.180 & 0.181 & 0.205 & 0.295 & 0.323 \\
\hline Number of Cantons & & 26 & 26 & 26 & 26 & 26 & 26 & 26 \\
\hline Canton FE & & YES & YES & YES & YES & YES & YES & YES \\
\hline Neighbour Cantons & & NO & NO & NO & NO & NO & YES & YES \\
\hline
\end{tabular}

Note: Minimum Wage Effects in Main Construction: Effect on Employment

Robust standard errors in brackets; ${ }^{* * *} p<0.01,{ }^{* *} p<0.05,{ }^{*} p<0.1$

Source: own elaboration of wage and employment data from the Swiss Labour Force Survey (SLFS) and minimum wage data from the collective labour agreements of the Swiss constructors' association (Baumeisterverband). 
In part with the obtained results we can accept for the Swiss case the original hypothesis formulated by Gilpin et al. (2006), who failed to prove the negative effect of labour market liberalisation in UK on employment. Furthermore, we can confirm the evidence from the collection of several works in the minimum wage literature, resumed by Neumark and Wascher (2008). Our results check the key results from the main empirical works in their collection, stating that high minimum wages close to the median wage have a negative impact on employment.

\section{CONCLUSIONS}

The liberalisation of the Swiss labour market with the adoption of the FZA agreement changed the employment effects of rising minimum wages in the construction industry. In the time preceding the introduction of the bilateral agreement in situations of rising minimum wage bites, employment continued to grow. As labour productivity remained constant, the data suggest that the higher labour costs were forwarded to consumers, implying higher construction prices, as long as the markets remained closed. The construction market allowed for larger margins and the absorption of higher wage costs by enterprises. After the application of the bilateral agreements between Switzerland and the European Union, the dynamics in the industry changed. A higher minimum wage bite reduced the growth of employment in construction. Moreover, the descriptive statistics show stagnating construction prices. This means that in a liberalised labour market and in a more open market construction firms do not dispose of instruments to cover higher wages for workers actually employed below the next year's minimum wage. Assuming that the actual wage of a worker would respect his marginal productivity, then a new minimum wage at a higher level would no longer justify the work relationship, and the firm would replace the employee. The observed results confirm that the liberalised labour market and, in general, open markets affect the employment decisions of involved firms through higher competition. Therefore, in years with growing minimum wage bites, employment growth slows down.

In the opposite case, following the obtained results, a country that seals off its markets and labour markets from an interconnected economic space could pay minimum wages above the marginal productivity of its workers, imposing higher margins. In this case, the considered firms would forward costs to the output, making the final consumer pay, and would therefore be able to maintain a larger workforce through the gained market power. Future applications of our method could in this way study the specific context of the Brexit case, whether the conclusions from this work could apply to the opposite case, and if the corresponding results would confirm a reversibility of effects when disintegrating labour markets.

A further extension of this research could be the application of our methodology to an industry with a relatively low minimum wage. According to Neumark and Wascher (2008), the effect of minimum wage on labour market outcome depends on the distance of the minimum and median wage. Since the construction industry has a high minimum wage compared to the median, it could be interesting to extend this study into an industry with relatively low minimum wages. Moreover, many Central and Eastern European countries have national statutory minimum wage systems, which could be similarly analysed.

A limitation of this research certainly lies in the fact that it takes several assumptions on economic conditions during the analysed period. The effect was analysed in a 
box, without taking into account other shocks that occur in the meantime and might affect each of the cantons in a heterogeneous manner. Secondly, the construction industry - offering standardised rules and data for all of Switzerland - constitutes only a small part of the entire economy, making it difficult to generalise conclusions for the remainder of the economic sectors.

Therefore, a deep analysis of the different effects of minimum wages constitutes scope for future research, as soon as larger and more complete data sets on this topic become available.

\section{REFERENCES}

Abadie, A. (2005). Semiparametric Difference-in-Differences Estimators. The Review of Economic Studies, 72(1), 1-19.

Author, D.H. (2003). Outsourcing at Will: The Contribution of Unjust Dismissal Doctrine to the Growth of Employment Outsourcing Semiparametric Difference-in-Differences Estimators. Journal of Labor Economics, 21(1), 1-42.

Bachmann, R., Konig, M., \& Schaffner, S. (2012). Lost in transition? Minimum wage effects on German construction workers. Ruhr Economic Papers, 358.

Baumeisterverband (2016). Website Schweizerischer Baumeisterverband SBV -2016 - Zahlen und Fakten. Retrieved from http://www.baumeister.ch/de/politik-wirtschaft/publikationen/zahlen-und-fakten on September 15, 2017.

Bertrand, M., Duflo, E., \& Mullainathan, S. (2004). How much should be trust Difference-in-Difference estimates. The Quarterly Journal of Economics, 119(1), 249-275.

Brochu, P., \& Green, D. (2013). The impact of minimum wages on labour market transitions. Economic Journal, 123(12), 1203-1235.

Cahuc, P., Carcillo, S., \& Zylberberg, A. (2014). Labor Economics (second edition). Cambridge, MA: MIT Press.

Card, D. (1992). Using Regional Variation in Wages to Measure the Effects of the Federal Minimum Wage. Industrial Labor Relation Review, 46, 22-37.

Dolton, P., Bondibene, CR., \& Wadsworth, J. (2010). The UK National Minimum Wage in Retrospect. Fiscal Studies, 31, 509-534.

Dolton, P., Bondibene, CR., \& Wadsworth, J. (2012). Employment, Inequality and the UK National Minimum Wage over the Medium-Term. Oxford Bulletin of Economics and Statistics, 74, 78-106. http://doi.org/10.1111/j.1468-0084.2011.00653.x

Dube, A., Lester, TW., \& Reich, M. (2010). Minimum Wage Effects across State Borders: estimates using contiguous countries. The Review of Economics and Statistics, 92(4), 945-964.

Dustmann, C., Frattini, T., \& Preston, I. (2013). The Effect of Immigration along the Distribution of Wages. Review of Economic Studies, 80, 145-173. http://doi.org/10.1093/restud/rds019

EDA (2017). Personenfreizügigkeit - Bilateral Abkommen I 1999. Retrieved from https://www.eda.admin.ch/content/dam/dea/de/documents/fs/04-FS-Personenfreizuegigkeit_de.pdf on June 3, 2017.

Favre, S. (2011). The Impact of Immigration on the Wage Distribution in Switzerland. Retrieved from http://www.econ.uzh.ch/static/wp/econwp022.pdf on July 2, 2017.

Gilpin, N., Henty, M., Lemos, S., Portes, J., \& Bullen, C. (2006). The Impact of free Movement of Workers from Central and Eastern Europe on the UK labour market. Retrieved from http://cream-migration.org/files/Working_paper_291.pdf on July 5, 2017. 
Giupponi, G., \& Machin, S. (2018). Changing the Structure of Minimum Wages: Firm Adjustment and Wage Spillovers. IZA DP, 11474. Retrieved from http://ftp.iza.org/dp11474.pdf on September 7, 2018.

Kampelmann, S., Garnero, A., \& Rycx, F. (2013). Minimum wages in Europe: does the diversity of systems lead to a diversity of outcomes? (Report 128). Etui. Retrieved from https://www.etui.org/content/download/11381/96227/file/13+R+128+Minimum+wages+Web+version.pdf on August 18, 2018.

Mortensen, D., \& Pissarides, C. (1994). Job Creation and Job Destruction in the Theory of Unemployment. The Review of Economic Studies, 61(3), 397-415.

Neumark, D., \& Wascher, W. (1999). Employment effects of minimum and subminimum wages: panel data on state minimum wage laws. Industrial Labor Relation Review, 46, 55-81.

Neumark, D., \& Wascher, W.L. (2008). Minimum wages. Cambridge, MA: MIT Press.

Portugal, P., \& Cardoso, A.R. (2006). Disentangling the minimum wage puzzle: an analysis of worker accessions and separations. Journal of the European Economic Association, 4(5), 988-101.

Steward, M. (2002). Estimating the impact of the minimum wage using geographical wage variation. Oxford Bulletin of. Economics and Statistics, 64, 583-605.

Verein-Grenzgänger: Bilaterale Verträge. Retrieved from http://www.grenzgaenger.de/bilaterale_vertraege.htm (2013) on March 1, 2013.

Van den Berg, G., \& Ridder, G. (1998). An Empirical Equilibrium Search Model of the Labor Market. Econometrica, 66(5), 1183-1221. http://doi:10.2307/2999634

vom Berge, P., \& Frings, H. (2019). High-Impact minimum wages and heterogeneous regions. Empirical Economics. https://doi.org/10.1007/s00181-019-01661-0 


\section{Authors}

The contribution of co-authors is equal and can be expressed as $50 \%$ for each of the authors: Luzius Stricker (LS) contributed to the literature review, worked on the preparation of the dataset. Moreno Baruffini (MB) contributed to the literature review. Both LS and MB reviewed the specific methods literature, conducted the analysis, and interpreted the obtained results.

\section{Luzius Stricker}

Luzius Stricker is a PhD student in Economics. He received his Bachelor's and Master's degrees in Economics at the Università della Svizzera italiana USI, and since 2014, he has been a collaborator of the Observatory for Economic Dynamics (O-De). His research focuses on wage policies and labour market reforms. His interests regional economic attractiveness, spatial planning, minimum wage effects and the impact of new labour market policies.

Correspondence to: Mr. Luzius Stricker, PhD Candidate, Istituto di ricerche economiche IRE Università della Svizzera italiana USI, Via Maderno 24 - CP, 4361, CH-6904 Lugano, Switzerland, e-mail: luzius.stricker@usi.ch

ORCID (1) http://orcid.org/0000-0003-1007-8605

\section{Moreno Baruffini}

Moreno Baruffini is an economist and environmental engineer. He works in the fields of regional sciences and statistics. He obtained his PhD degree from the Faculty of Economics, Università della Svizzera italiana (USI). He is currently the head of the Observatory for Economic Dynamics (O-De), Institute for Economic Research (IRE), Università della Svizzera Italiana (USI). He graduated with honours from the Politecnico di Milano (Italy). He worked at the METID Centre (Metodi e Tecnologie Innovative per la Didattica) at the Politecnico di Milano and at the Institute of Earth Sciences of the University of Applied Sciences of Southern Switzerland SUPSI.

Correspondence to: Dr. Moreno Baruffini, Post-Doc Researcher, Istituto di ricerche economiche IRE - Università della Svizzera italiana USI, Via Maderno 24 - CP, 4361, CH-6904 Lugano, Switzerland, e-mail: moreno.baruffini@usi.ch

ORCID (1) http://orcid.org/0000-0002-2347-6082

\section{Acknowledgements and Financial Disclosure}

The data that support the findings of this study are available from the Swiss Federal Office of Statistics (FSO) but restrictions apply to the availability of these data, which were used under license for the current study, and so are not publicly available. Data are however available from the authors upon reasonable request and with the permission of Swiss Federal Office of Statistics (FSO).

The authors would like to thank the anonymous referees for their useful comments, which allowed to increase the value of this article. We would also like to thank Prof. Rico Maggi who reviewed an earlier version of this research.

\section{Copyright and License}

This article is published under the terms of the Creative Commons

Attribution - NoDerivs (CC BY-ND 4.0) License

http://creativecommons.org/licenses/by-nd/4.0/

Published by Cracow University of Economics - Krakow, Poland 